\title{
NARRATOLOGICALAPPROACHES TO MULTIMODAL CROSS-CULTURAL COMPARISONS OF GLOBAL TV FORMATS
}

\author{
Edward Larkey \\ University of Maryland, Baltimore County \\ 1000 Hilltop Circle \\ Baltimore, MD 21250 \\ USA \\ larkey@umbc.edu
}

\begin{abstract}
This article cross-culturally compares different versions of the Quebec sitcom/sketch comedy television series Un Gars, Une Fille (1997-2002) by examining the various gender roles and family conflict management strategies in a scene in which the heterosexual couple visits the male character's mother-in-law. The article summarizes similarities and differences in the narrative structure, sequencing and content of several format adaptations by compiling computer-generated quantitative and qualitative data on the length of segments. To accomplish this, I have used the annotation function of Adobe Premiere, and visualized the findings using Microsoft Excel bar graphs and tables. This study applies a multimodal methodology to reveal the textual organization of scenes, shots and sequences which guide viewers toward culturally proxemic interpretations. This article discusses the benefits of applying the notion of discursive proximity suggested by Uribe-Jongbloed and Espinosa-Medina (2014) to gain a more comprehensive and complex understanding of the multimodal nature of cross-cultural comparison of global television format adaptations.
\end{abstract}

Keywords: Global Television, Television Format Adaptations, Cultural Proximity, Multimodal analysis, Crosscultural comparison, Gender Roles, Family Conflict Resolution Management

The rapid expansion of the global TV format trade in the last 20 years and its increased opportunities for the participation of smaller television markets such as Israel, Canada, Denmark, Sweden, Colombia and Spain mean that a single format may be reproduced in a large number of culturally and linguistically very different television markets. While reality and game shows have predominated in the global TV format trade and its scholarly reflection with shows like Who wants to be a Millionaire, Survivor, Big Brother, and the countless song, cooking, modelling, and investment competitions, this also holds true for scripted dramas and comedies such as Yo soy Betty, la fea (Colombia), The Office (UK), Desperate Housewives (US). Also, many Japanese dramas have been reproduced in Taiwan, China, Korea, Singapore, and other places, in addition to a large number of US series which have been re-made in Turkey, or Latin American telenovelas circulating among the various countries on that continent, as well as in Korea, the Middle East and Turkey.

With few exceptions, the Francophone market is largely excluded from more recent Anglophone scholarly scrutiny, even though France occupies the number 7 ranking on the 2008 FRAPA list ${ }^{1}$ of exported format titles (12), share of exported formats (4\%) and revenue generated from format export (€ 77 Million) in the year 2008, and the entry for Canada does not distinguish between Anglophone and Francophone Canadian productions. Therefore it benefits us to 
take seriously Francophone global format distribution, and especially the participation of the French-speaking television of Quebec exemplified by the Quebec sketch comedy series Un Gars, Une Fille (1997-2002)2, which has been reproduced in more than 28 different markets - and not only in the Francophone geo-linguistic area - since its inception, and continues to generate further iterations, most recently in the United Arab Emirates and a West AfricanFrench version (see Table 1).

Table 1. List of official versions of Un Gars, Une Fille produced until 2017 along with first year of broadcast. Courtesy of Avanti Cine Groupe.

\begin{tabular}{|c|c|c|}
\hline \multicolumn{3}{|c|}{ List of Versions of Un Gars Une Fille and Year of First Broadcast } \\
\hline Number & Country & Date of First Broadcast \\
\hline 1 & Canada & 1 May 1997 \\
\hline 2 & Belgium & August 1998 \\
\hline 3 & France & 11 October 1999 \\
\hline 4 & Sweden & November 1999 \\
\hline 5 & Portugal & May 2000 \\
\hline 6 & Greece & Autumn 2000 \\
\hline 7 & Spain & 22 September 2000 \\
\hline 8 & Bulgaria & 2002 \\
\hline 9 & Hungary & 2002 \\
\hline 10 & Netherlands & 2002 \\
\hline 11 & Israel & 9 July 2002 \\
\hline 12 & English Canada & September 2002 \\
\hline 13 & Poland & 3 September 2002 \\
\hline 14 & Germany & 13 October 2002 \\
\hline 15 & Mexico & 31 July 2003 \\
\hline 16 & Russia & 20 September 2003 \\
\hline 17 & Italy & 15 December 2004 \\
\hline 18 & Ukraine & 14 January 2005 \\
\hline 19 & Lebanon & 27 February 2006 \\
\hline 20 & Latvia & 20 October 2006 \\
\hline 21 & Lithuania & 29 August 2007 \\
\hline 22 & Turkey & 2 October 2008 \\
\hline 23 & Cyprus & 8 October 2010 \\
\hline 24 & Kazakhstan & 8 October 2012 \\
\hline 25 & Abu Dabi & July 2013 \\
\hline 26 & Czech Republic & 10 September 2013 \\
\hline 27 & Serbia and Montenegro & 5 October 2015 \\
\hline 28 & Slovenia & 6 March 2016 \\
\hline 29 & French Africa & 13 November 2017 \\
\hline
\end{tabular}

All 28 current official adaptations of the series feature interactions and conflicts between a non-married, yet cohabitating childless 30 -something heterosexual couple as it negotiates its relationship between the pressures of 
what family relations researchers have called the "de-institutionalization of marriage" and the erosion of the "heterosexual marriage monopoly"3.

The life of the Guy and the Girl ${ }^{4}$ deviates from the traditional sequence of events for family formation, consisting of courtship, engagement, marriage/co-residence, sex, children, empty nest etc. The couple illustrates what de Vaus points to as a re-ordering of those sequences which depart from conventional social scripts while pursuing the construction of one's own life narrative. De Vaus underscores the ambivalent nature of this undertaking: on the one hand, its complexity can be welcoming and liberating, but it can also be "profoundly unsettling," particularly without the guidance of those established social scripts. In addition, the continual re-negotiation of domestic roles can be both exhilarating yet exhausting and complicated for the couple.

Table 2. TV series "inspired by" Un Gars, Une Fille with no officially concluded contract between Avanti Cine Groupe and the domestic producers. Compiled by the author.

\begin{tabular}{llr}
\hline & TV Series “inspired by" Un Gars, Une Fille & \\
\hline Title of Series & Country of Origin & Year(s) of Broadcast \\
\hline Sousou et Nounou & Algeria-Arabic & 2007 \\
Timsal n Wexxam & Algeria-Kabyle & 2014 \\
Le Couple & Morocco & 2013 \\
lyz m'tsam & Madagascar & $2013-2018$ \\
Love Bytes & India & $2015-2017$ \\
Mann/Frau & Germany & $2014-2015$ \\
Bent Walad & Tunesia & 2012 \\
Polovinki & Russia & $2012-2013$ \\
Sasho i Sashka & FYR Macedonia & $2005-2006$ \\
\hline
\end{tabular}

Contemporary couples, including those depicted in various versions of Un Gars, Une Fille, continually re-negotiate both the division of domestic labour in the household, as well as the degree of autonomy of each participant in the relationship, without necessarily relying on behavioural patterns and ways of thinking of previous generations. Still, as Allen and Walker, summarizing their own and others' previous research ${ }^{5}$, have determined, "both old and new ideas about gender and old and new gender practices coexist" in the same families simultaneously. Therefore, various versions of Un Gars, Une Fille ${ }^{6}$ display a wide variety of culturally specific negotiating strategies over gender roles, conflicts, and their resolutions within the narrative framework of the television format as those narratives travel from market to market across national and geo-linguistic boundaries. While I will not delve into the cultural specifics of each depiction, I will display some similarities and differences in the structure and content of the televisual texts which form the starting point for further analyses of culturally specific gender and family negotiating strategies as the narrative structure, content and sequencing is transformed to achieve greater cultural proximity.

3 David de Vaus, 'Social Trends and their Impact of Couple and Family Relationships,' Patricia Noller and Gery C. Karantzis, eds., The WileyBlackwell Handbook of Couples and Family Relationships, Wiley-Blackwell, 2012, p. 26.

4 In this article, I will be referring to the main characters of this series as "the Guy" and "the Girl", while in the specific scene I will be investigating, I will be referring to the "Mother-in-Law" when referencing the character from the standpoint of the Guy, and as the "Mother" when referencing the character from the standpoint of the Girl.

5 Katherine R. Allen and Alexis J. Walker, 'Constructing Gender in Families,' in Robert Milardo and Steve Duck, eds, Families as Relationships, Wiley, 2000, p. 4.

6 Unless otherwise indicated, I will be referring to the Quebec original version of the series when making general statements or descriptions of the narrative. 
E. Larkey, Narratological Approaches to Multimodal Cross-Cultural Comparisons of Global TV Formats

This series offers an excellent platform for a transnational study of format adaptations which would allow for the computer-supported quantitative measurement of both transnational as well as local components of the different versions. The current study takes its cue from Bateman and Schmidt ${ }^{7}$ to describe and illustrate a cross-cultural, comparative, multimodal methodology for analysing the narrative structure, content and sequencing to discern the textual organization of scenes, shots and sequences which organize and guide the viewers toward their respective interpretations. This study will follow suggestions by Bateman and Schmidt that the notions of spatiality, temporality, and sequentiality are crucial points of orientation for discerning its audience-guiding textual organization.

\section{Measuring Transnationalism of Television Formats: Multimodal Approaches to Cultural and Aesthetic Proximity}

This study can be seen as a response to a call by Redfern ${ }^{8}$, in his polemic against the Society for Cinema and Media Studies' reluctance to engage with quantitative research on film, to pursue a multidisciplinary incorporation of quantitative methods into the study of film, and by extension, television, which will "help us answer questions about the economics of the film industry, about the patterns in the style and form of motion pictures, about audiences'

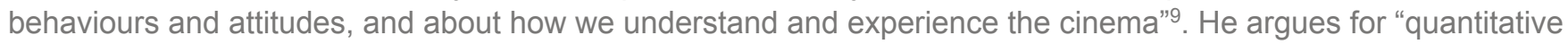
literacy" and supports the inclusion of quantitative methods into educating film and media students so that film scholars can acquire the skills necessary to "participate in evidence-based policymaking"10. Butler ${ }^{11}$ also underscores the utility of collecting quantitative data on editing techniques because "it is relatively simple to measure the lengths of shots and thus convert a qualitative, stylistic component into quantitative data" to store in a database for further assessment and manipulation.

Previous studies of global TV format adaptations of scripted dramas and comedies have been rooted in concepts of cultural proximity, which are efforts of television format producers to cater to audiences who prefer programming close to their own culture(s). Chalaby states that formats are a "platform on which to generate drama" and are both international and local since they only achieve international success when they are popular among national, regional, or local markets ${ }^{12}$. Moran calls a format a "recipe or guide to the remaking of a programme adaptation in another territory," using the original as a "template" to guide the reproduced adaptation ${ }^{13}$. Van Keulen ${ }^{14}$ proposes a concept of "aesthetic proximity," which is the ability to "generate aesthetic characteristics and stylistic norms that are shared by an increasing number of countries" and are thus transnational in nature, while simultaneously displaying "local styles and diversity". She considers these local aesthetic and stylistic elements, i.e., the "surface," an "important layer of format localization"15. It is clear that aesthetic proximity and cultural proximity, which "also includes language, but also dress,

7 John A. Bateman and Karl-Heinrich Schmidt, Multimodal Film Analysis. How Films Mean, Routledge, 2012.

8 Nick Redfern, 'Quantitative methods and the study of film,' Invited Lecture, University of Glasgow, 2015. Typescript. Accessed on Feb 1, 2019 at http://citeseerx.ist.psu.edu/viewdoc/summary?doi=10.1.1.697.8815

9 Redfern, 2015, p. 5.

10 Redfern, 2015, p. 11.

11 Jeremy G. Butler, 'Statistical Analysis of Television Style: What Can Numbers Tell Us about TV Editing?,' Cinema Journal 54, 1, Fall $2014,27$.

12 Jean K. Chalaby, The Format Age. Television's Entertainment Revolution, Polity, 2013, p. 55.

13 Albert Moran, 'Makeover on the move: Global television and programme formats,' Continuum: Journal of Media \& Cultural Studies, 22, 4, August $2008,461$.

14 Van Keulen, 'Aesthetic Proximity. The role of stylistic programme elements in format localisation,' VIEW Journal of European Television History and Culture, 8, 9, 2016.

15 Van Keulen, 2016, p. 4. 
ethnic types, body language, definitions of humour, ideas about story pacing, music tradition, religious elements"16 and other aspects ${ }^{17}$ refer to different modes of communication, which is why an analysis of different versions of the television format Un Gars, Une Fille would benefit from a multimodal analysis such as that proposed here.

Calling Un Gars, Une Fille a sketch comedy series is somewhat of a misconstrual. Most sketch comedy series are characterized by almost randomly organized short sequences, which, by themselves, do not necessarily produce a narrative cohesion in the sense of a beginning, exposition, and end of the narrative such as that encountered in Un Gars, Une Fille. Certain characteristics of the series would seem to fulfil Mittell's definition of a "complex television" narrative, "a cumulative narrative that builds over time"18 in which "multiple frames of the past, present, and future" are managed in making sense of the storyworlds ${ }^{19}$. While the label as sketch comedy does not commit the series to a coherent or linear narrative, the definite sequentiality and seriality of the series, with its maintenance of a narrative world over time and a consistent set of characters, blurs the boundaries to a variety of different genres, including foremost sitcom and sketch comedy.

In concurring with Mittell that "time is an essential element of all storytelling"20, I assert in approaching a multimodal cross-cultural analysis of the various versions of Un Gars, Une Fille that it is possible to compile quantitative data and measure the temporal durations of the various segments of different modes and compare these in an effort detect culturally and aesthetically specific localized, and transnational multimodal components which will assist in the crosscultural interpretation of those versions as particular contested iterations of a global discourse. Jewitt, O'Halloran and Bezemer ${ }^{21}$ propose that a multimodal analysis should "describe, transcribe, annotate and analyse materials at a micro level, that is, "with attention to the fine-grained detail of form and meaning" in order to produce "rich, detailed metalanguages for theorizing about the social world"22. Therefore, I will focus my multimodal analysis on what I am labelling the Mother-in-Law scene(s), scrutinizing in detail a climactic shot in which a conversational confrontation takes place between the Guy and the Mother-in-Law. This means I will be engaging in what Norris ${ }^{23}$ calls a "multimodal interaction analysis" which involves understanding and describing "what individuals express and others react to" in a specific interaction ${ }^{24}$. My focus will be on the confrontational dialog between the Guy and his Mother-inLaw and examine in greater detail the idiosyncratic deployment of what I am labelling "sad" music in the shot to generate sympathy with different characters in the different versions to realize culturally distinctive objectives and identifications.

\section{The Series Narrative}

Un Gars, Une Fille features an approximately 30-40-year old non-married, childless, heterosexual couple as it interacts with each other, friends and relatives in domestic private spaces, and with other strangers and acquaintances in public and commercial spaces outside of their domicile, such as at a fitness centre, the supermarket, a liquor store, a shopping mall, camping outdoors, riding in a car and in a sex toy store. Many versions of the series use the actual names of the actors and actresses for the names of the main characters. In the original Quebec version these are

16 Joseph D. Straubhaar, World Television. From Global to Local, Sage, 2007, p. 26.

17 see Antonio La Pastina and Joseph D. Straubhaar, 'Multiple Proximities between Television Genres and Audiences,' Gazette. The International Journal for Communication Studies, 67, 3, 2005, pp. 271-288.

18 Jason Mittell, Complex TV: The Poetics of Contemporary Television Storytelling, 2012, NYU Press, p. 11.

19 Ibid., p. 26.

20 lbid., p. 26

21 Cary Jewitt, Jeff Bezemer and Kay O’Halloran, Introducing Multimodality, Routledge, 2016.

22 lbid., p. 7.

23 Sigrid Norris, Analyzing Multimodal Interaction: A Methodological Framework, Routledge, 2004.

24 Ibid., p. 4. 
"Silvie" (Leonard) and "Guy" (Lepage, who is also the creator and writer of the series). The episodic and some of the non-episodic versions of the series separate

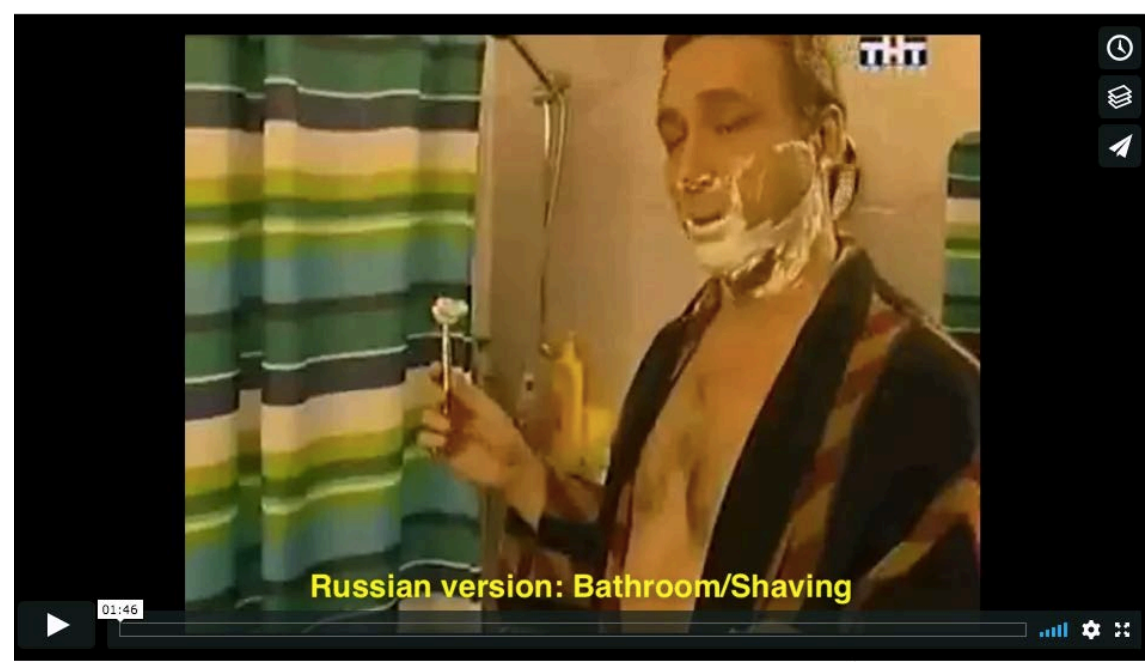

Video 1. Pre-visit shots from different versions of Un Gars, Une Fille depicting spaces and activities in which the motivations for visiting the Mother-in-Law is performed by the Guy and the Girl.

the various shots and scenes with characteristic music and visual transition cues situated in similar places in the narrative according to the preceding topic of discussion between the characters. A compilation of these transitions for the Mother-in-Law scene(s) [Season 1, Episode 1; Season 2, Episode 2] can be found in the video clip 2.

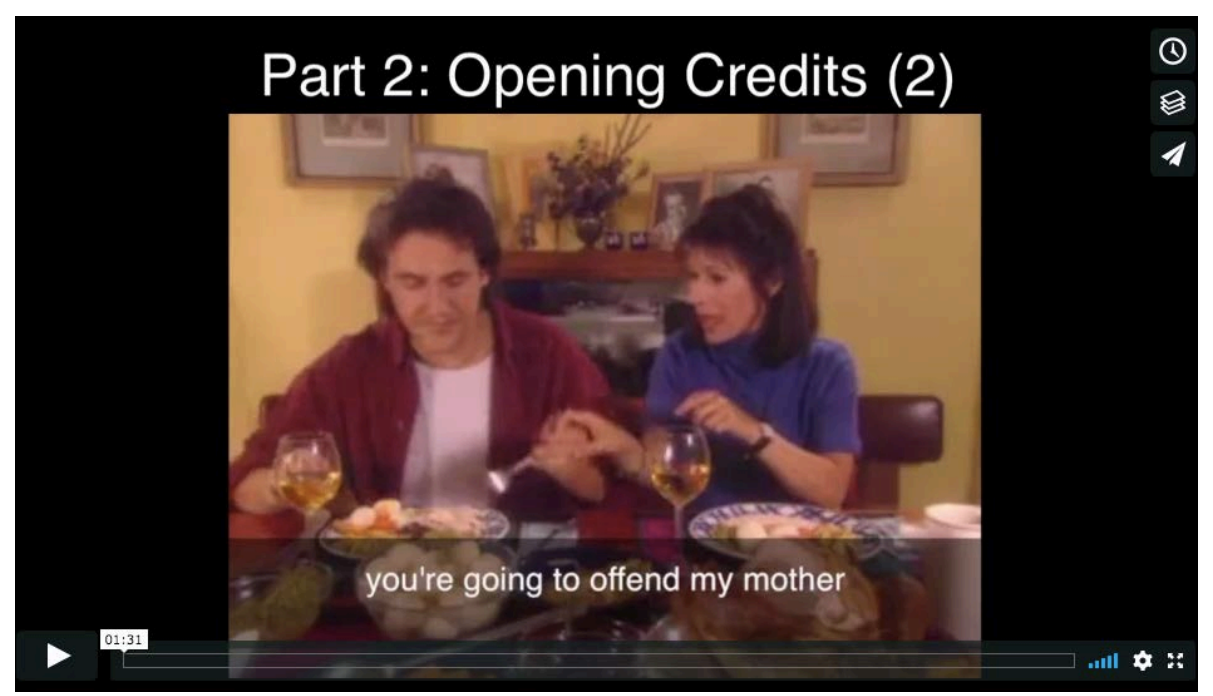

Video 2. Compilation of transitions between each shot in the original Quebec version Un Gars, Une Fille. These transitions include the audio track with music, visuals with graphics and writing, as well as fade-out and fade-in to separate the various shots in both Parts 1 and 2 of the Mother-inLaw scene.

This study will draw on approximately 10 different versions of the series ${ }^{25}$ and focus specifically on a scene in which the couple visits her mother, who, in a pre-visit segment, is revealed to harbour a great deal of animosity towards

25 With the exception of the Quebec, French, and Polish versions, I have accessed most versions of the series from YouTube, assuming that they would continue to be available by the time I have completed this article. This has not happened, and as a result several episodes of several versions are no longer available, even though I have them at my private disposal. In addition, the German version (entitled Du und ich - "You and I") 
the Guy. This animosity emerges during a bathroom shot of the pair prior to the visit usually placed in the same episode as the first part of the visit. In this bathroom scene, the male protagonist is either shaving, brushing his teeth or cutting the hair in his nostrils. The Girl desires to visit her mother in the interest of emotional bonding, but the Guy initially refuses, making reference to the antagonism between the two, insisting that he is opposed to the meeting "as a matter of principle". The Girl however, is not to be deterred and initiates an act of oral sex to seduce him into agreeing to go, the outcome of which is delayed for the viewer until one or two scenes further in the episode when the couple is sitting at the Mother-in-Law's dining room table. I have compiled edited selections of these from various versions into the video clip 1.

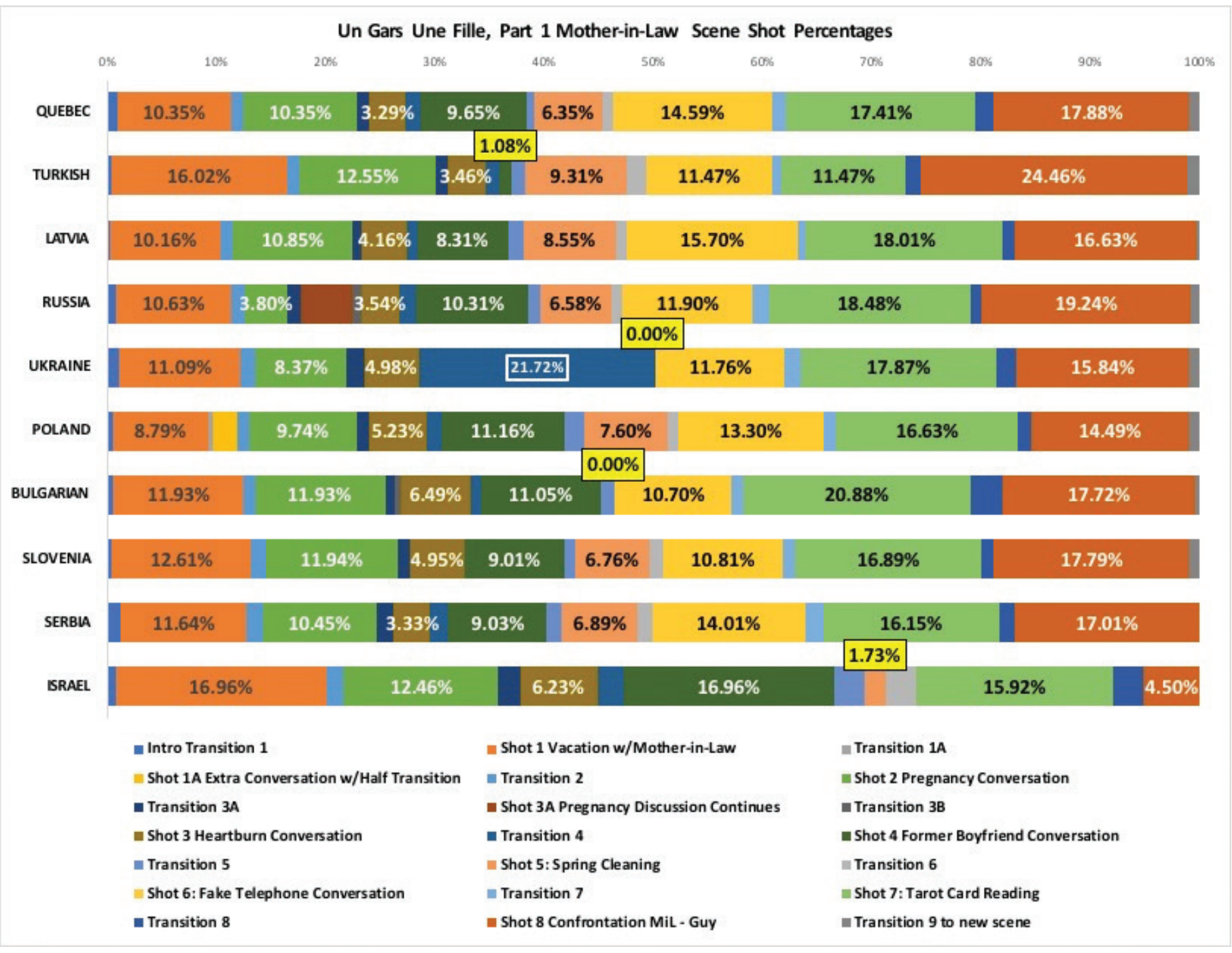

Figure 1. Bar graph of 10 different versions of Un Gars, Une Fille (Season 1, Episode 1; Part 1 of the Mother-in-Law scene) showing the relative lengths and positions of each shot in percentages, along with a display of locations oft he transitions in those versions.

was only available through the services of the archives of the Zweites Deutsches Fernsehen, who graciously consented to transfer episodes 1-9 from VHS cassettes to DVD for my research. These, however, are private copies and not available for general audiences. Finally, only one episode (episode 8) of the Ukrainian version Леся и Рома, comprising a part of this study, was available at the time of the revision of this article, while the other episode, number 5, was no longer available. Instead, a new version of the series was broadcast in 2018 entitled Марк и Наталка featuring different actors, a different set, and different sequencing of shots and scenes. 
In the episodic versions ${ }^{26}$, the visit itself is divided into two parts: the first part (see Figure 1 bar graph of Part 1) usually features the mother serving cake and coffee while various conversations among the three characters take place about a possible pregnancy, previous relationships and tarot card readings; the second part (see bar graph of Part 2) displays a dinner and various after-dinner activities such as playing the board game Monopoly, discussions about the relationship between mother and daughter, and finally, a shot of the couple leaving the Mother-in-Law's apartment/house overburdened with leftovers. A compilation of the ways leaving the mother-in-law's house/apartment has been depicted in various versions can be seen in video clip 3, in which the impatience of the Guy is manifested both in his physical actions in the scene, as well as reinforced by the staging of the couple in the frame by the camera.

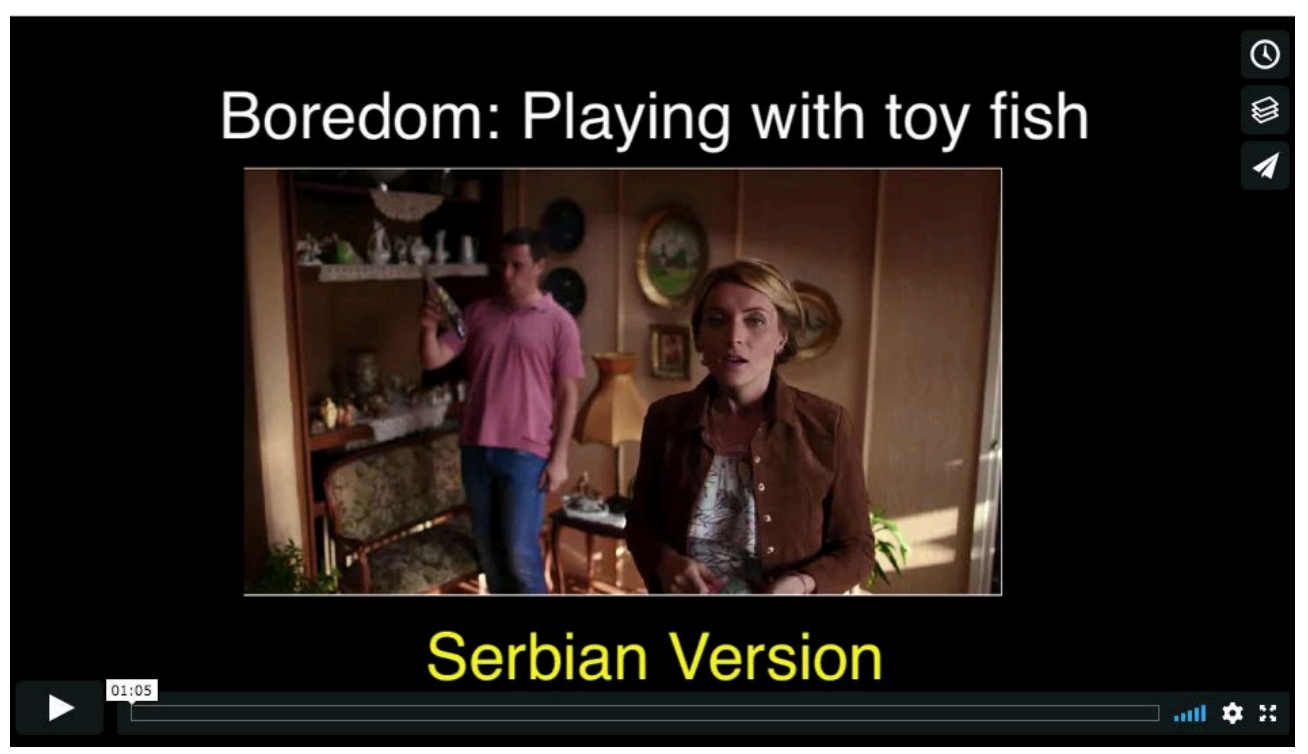

Video 3. Compilation of the final shot of the various versions in which the impatience of the character(s) is staged differently. Usually the Guy is driving the tension and is most impatient.

The bar graph in Fig 3 represents the lengths and proportions of shots in Part 1 of the Mother-in-Law scene (Season 1, Episode 1). It contains the percentages of duration of each shot relative to the overall length of the scene, and includes the proportional duration of the transitions between each shot. The different versions of Part 1 reveal that there is no conversation about the former boyfriend in Episode 5 the Ukrainian version, and neither the Israeli ${ }^{27}$ (Episode 4) nor the Bulgarian version ${ }^{28}$ (2002-2004) features a conversation about spring cleaning and doing away with (the Girl's) messiness. The bar graph also indicates that the confrontation between the Mother-in-Law and the Guy in the last shot is the longest shot among most of the different versions, followed by the (tarot) card reading shot. In addition, the bar graph brings to light an extra segment in Episode 2 of the Russian version ${ }^{29}$ (2003-2005) continuing the conversation about a possible pregnancy.

26 There are episodic versions of the series and non-episodic versions. The non-episodic versions are the French, the Italian, the Spanish, which are much shorter and usually broadcast between longer television broadcasts in the schedule. The episodic versions are the Russian, Ukrainian, Quebecois, Polish, Turkish, Latvian, Serbian, Slovenian, Macedonian, Bulgarian, and Greek. The Greek is an anomaly among the episodic versions in that several scenes and shots are added which are not in the others. The German is also an anomaly in that the narrative structure is modified whereby the motive for visiting the Mother-in-Law is not because of the feelings of the Girl for her mother, as in the other versions. Instead, the motivation for visiting the Mother-in-Law exists because the Girl threw away the documentation for deducting income tax write-offs and the couple now owes money they didn't budget for that they hope they can "borrow" from the Mother-in-Law.

27 Youtube.com: https://www.youtube.com/watch?v=wkpXEpKEAEQ accessed on January 27, 2019.

28 Entitled Тя й Tou, Episode 3, Youtube, https://noviseriali.com/тя-и-той-сезон-1-епизод-3_be60d6143.html, accessed on January 29, 2019 29 Саша и Маша, Youtube, https://www.youtube.com/watch?v=rp9hVTe6694\&list=PLSFxyBocXuT8YDpBr3ptFtXJuyaXpt07, accessed on January 28, 2019. 
For this investigation, I have reconstructed and transformed the narrative of the scene into a coherent and almost linear continuous story, i.e., the visit to the mother-in-law, to delineate the beginning (the seduction shot in the bathroom), the two parts of the visit (coffee and cake in Part 1 and dinner in Part 2), and leaving the mother-inlaw's place to conclude the scene. The monospatial character of the shots of the visits tends to mask the fact that they take place at different periods, as a video compilation of stills reveals. The temporal discontinuity between the two parts is signalled both by the noticeably different clothing worn by the couples in each part, as well as the fact that they occur in different episodes that are temporally far apart (i.e., in some cases, weeks) in the broadcast schedule. Stills of the two different parts illustrating the difference in clothing, lighting, and sometimes camera angle and seating configuration can be seen in video clip 4, which also indicate the specific episodes for each version.

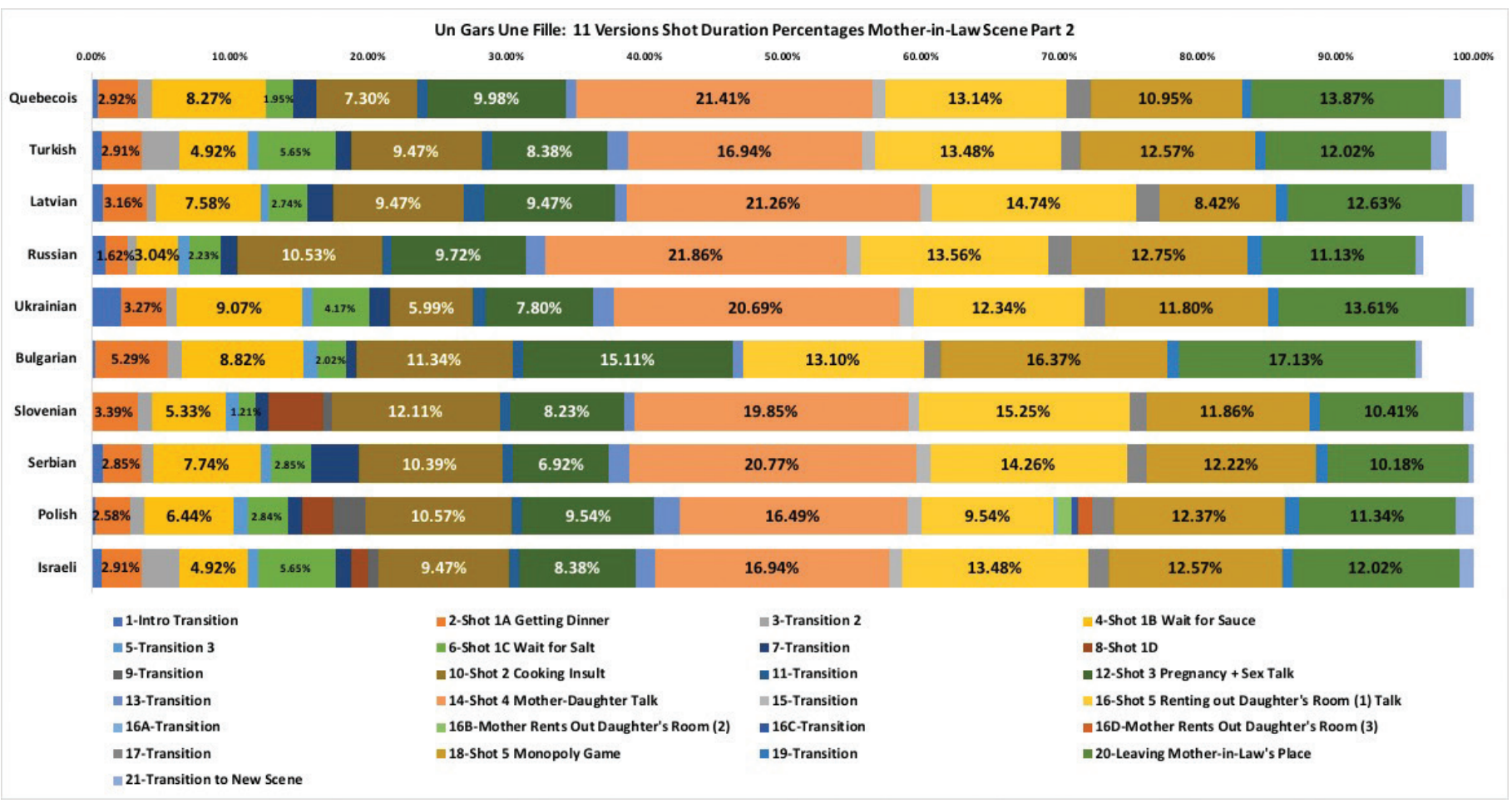

Figure 2. Bar graph of 11 versions of Un Gars, Une Fille (Part 2 of the Mother-in-Law scene) showing the relative lengths and positions of each shot in percentages, along with a display of locations of the transitions between the shots.

In the Part 2 sequence of shots (Season 2, Episode 2), the bar graph illustrates that the Bulgarian version has excluded the longest shot of all other versions, i.e., the Mother-Daughter conversation initiated through mentioning the book My Mother, My Mirror ${ }^{30}$. Only the German version ${ }^{31}$ neglects to include this shot within the respective episode, but the German version is only half the length of both mother-in-law scene parts of the others. In the Bulgarian version, the longest segment therefore is the leaving segment, which highlights more forcefully the animosity between the male protagonist and his mother-in-law, while downplaying the conflict between the daughter and the mother featured in the excluded segment.

The Mother-in-Law scenes are excellent objects of investigation for various reasons related to both transnational and local components of the narrative. The transnational elements include the aforementioned 
monospatial set in which the encounter between the couple and mother-in-law transpires in the dining room only. In addition, in the earlier versions the camera is largely stationary, situated behind a shoulder of the Mother-in-Law (on either the left or the right), or as a point-of-view camera in which the Mother-in-Law is completely out-of-frame and present only as a disembodied voice. In some of the later versions, part of the Mother-in-Law's head, arms, and in the Bulgarian version even the front of the face and half of the body from the side are in the frame. In later versions such as the Slovenian ${ }^{32}$, even the monospatial set is abandoned and the conversations and action take place in various different rooms of a house on set. In most versions, the characters are depicted sitting at the dining room table such that only their torso, arms, hands, face, eyes and hair are visible.

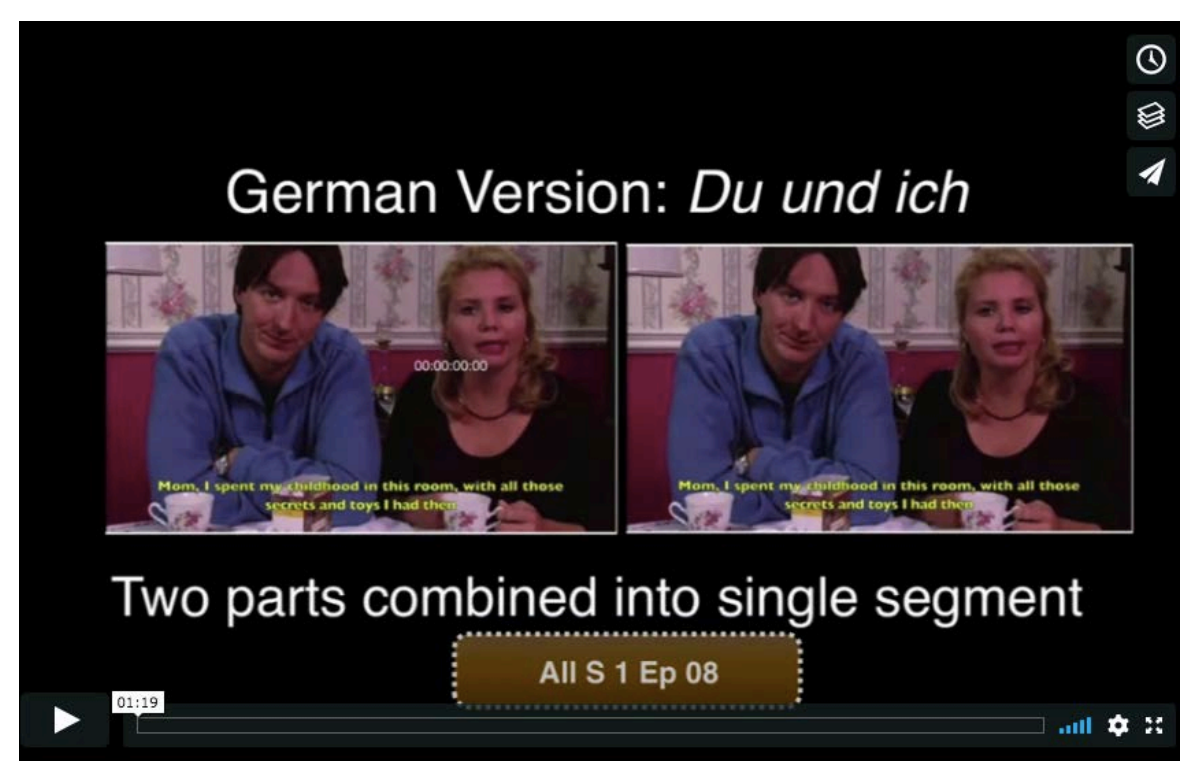

Video 4. Compilation of screen shots showing the spatial and chromatic similarities and differences in the mis-en-scene of Parts 1 and 2 in various versions of Un Gars, Une Fille. The compilation indicates the episode and season from which each screen shot was taken.

Due to the monospatial setting and stationary camera, for the purposes of structure, I have divided the shot sequences, of which there are approximately 19 or 20 , into activities and conversation topics ${ }^{33}$ approximately distinguished by the series transitions. In addition, I created the bar graphs to represent the lengths and proportions of shots in Part 1 of the Mother-in-Law scene containing the percentages of each shot duration relative to the overall length of the scene, and including the proportional duration of the transitions between each shot. The bar graph also indicates that the confrontation between the Mother-in-Law and the Guy in the last shot is the longest shot among most of the different versions, followed by the (tarot) card reading shot. In this case, therefore, the longest shot appears to be the most important in the sequence of shots.

The bar graphs of both Part 1 and Part 2 (Figures 1 and 2) display the proportional lengths of each shot relative to the total length of the scenes. Especially the activities and some of the conversation topics are delineated by the specific music and visual transitions mentioned above. Most of the versions retain the same general sequence of shots, with 
some versions inserting a topic or leaving out a particular conversation or activity ${ }^{34}$. However, the two parts of the mother-in-law visit are divided in the same manner (at the same point) in most of the versions. A more detailed transcultural analysis would uncover culturally salient reasons for the deletions, additions or modifications in the different versions relative to the original.

\section{UN GARS, UNE FILLE GUY VS MOTHER-IN-LAW, \% OF "WINS" IN SHOTS}

$70.00 \%$

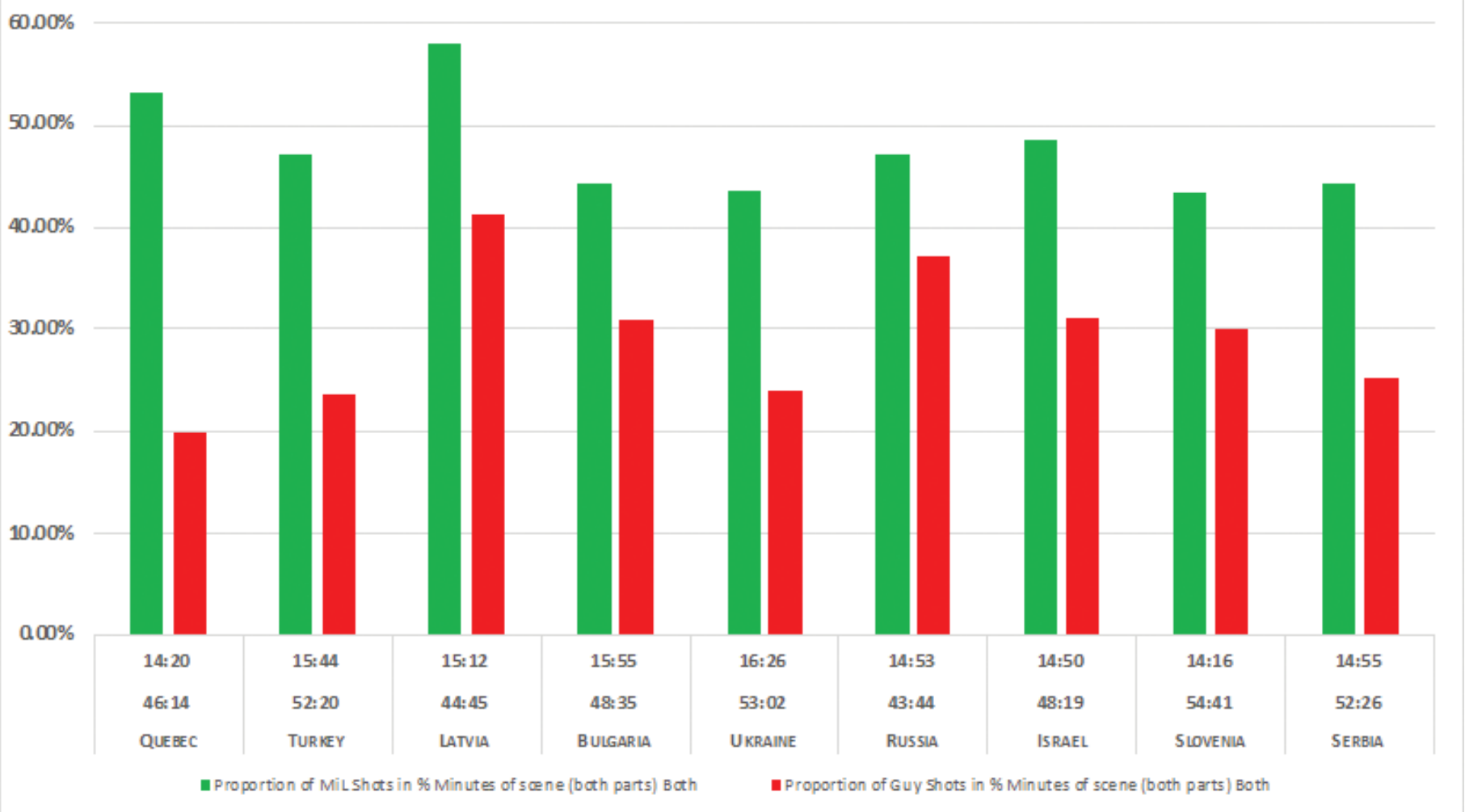

Figure 3. Bar graph showing how much the Mother-in-Law and the Guy "won" the respective confrontation in each shot of Parts 1 and 2 of the Mother-in-Law scene in each version. The bar graph illustrates the predominance of the Mother-in-Law compared to the Guy.

I will be using the narratological concepts summarized by Jeremy Butler ${ }^{35}$ to describe how the mother-in-law scene(s) are constituted. The pre-visit scene sets up the aforementioned narrative enigma between the protagonist (the Guy) and the antagonist (the Mother-in-Law) prior to the introduction of the audience to the Mother-in-Law, in which a question is explicitly or implicitly asked ${ }^{36}$ and whose resolution is blocked by the

34 Different versions include or exclude different segment: The Turkish version, for instance doesn't include the tarot card segment of the other versions, and the Bulgarian version doesn't include a mother-daughter conversation that characterizes a main conflict between the two. The idiosyncratic German version doesn't include the Guy-Mother-in-Law confrontation in a separate shot but distributes the confrontations throughout the episode The Greek series includes a new scene with the Mother-in-Law in restaurant, while the French does not include an actual confrontation with Mother-in-Law at the dinner table but has 2 extra shots in which the Guy has daydreams against the Mother-in-Law. The daydream scenes do not reveal themselves to be daydreams until the final frames using an out-of-focus transition to bring the viewer back to the current reality, thus initially confusing the viewer into thinking that the two segments are real confrontations, while their real staging as daydreams is only revealed at the end of the sequence. The Ukrainian version adds a shot in which mother and daughter sing a folk song together.

35 Jeremy G. Butler, Television. Critical Methods and Applications, Routledge, $4^{\text {th }}$ edition, 2012.

36 Ibid., p. 26. 
antagonist, i.e., the Mother-in-Law. In this case the question is: "Why does so much animosity exist between the Mother-in-Law and the Guy?" The answer to this question is delivered in the last shot of Part 1 of the scene, which will be the object of further comparative multimodal study below in this paper. This conflict sets the stage for the encounter at the Mother-in-Law's house/apartment in which she actively antagonizes the Guy, and other segments in which he actively antagonizes her. However, each person engages in different kinds of conflict management strategies of which I will provide greater detail further below. I have set up a "scorecard" table summarizing these conflicts, which according to Butler ${ }^{37}$ represents a cause-and-effect chain, or actions and reactions constituting the progress of the narrative, whereby one of the characters "wins" while the other "loses" in a series of actions or events.

This is depicted in a bar graph in Figure 3. The table shows that in spite of her onscreen physical absence, the Mother-in-Law overwhelmingly dominates the conversation in these scenes in terms of the amount of time afforded to her dialog, and thus achieves more "wins" against the guy. The overbearing presence of the values and attitudes of the Mother-in-Law in these depictions in spite of her physical absence suggests that the values of the representative of the older generations are still quite powerful forces influencing social behaviour and discourses in the lives of the younger generations. The personality traits of the Mother-in-Law as well as her space of habitation, which according to Butler ${ }^{38}$ are part of the "exposition," are on display throughout these exchanges and explain "who the characters are and what their space entails." The fact that the immobile camera stays focused on the Guy and the Girl in the Mother's dining room throughout the scene corresponds to the Mother's narrow and conventional outlook on what a "proper" and conventional family is supposed to be. The conflict is not resolved at the end of the scene when the couple is leaving with the leftovers from the meal, so neither the scene nor the narrative reverts back to an initial state of reconciliation as in a sitcom. This lack of resolution and the casual and non-institutionalized nature of the relationship of the Guy and the Girl indicates that negotiating strategies around gender roles and family relationships are always in a state of flux and therefore unstable if they are not "institutionalized" and thus legitimized.

In most versions, the Mother-in-Law is shown to be very concerned that her daughter becomes pregnant, has a baby and starts a family with grandchildren, and not be with the Guy. The Mother-in-Law is shown to be competitive, egotistical, not very empathetic to the daughter's feelings, but also direct, inquiring explicitly about their sex life and admonishing them not to use contraceptives. The Mother-in-Law takes particular glee in beating the Guy in a game of Monopoly, and makes pointed remarks about the (Mother-in-Law's favourite) former boyfriend of the Girl to reiterate her animosity to the Guy, in spite of ineffectual efforts by the daughter to prevent her from broaching or expounding on the topic. The Guy counters this by remarking that the former boyfriend must be gay to continue to write birthday messages to the Mother-in-Law long after the relationship to her daughter has ended. The Guy defends himself and returns the favour to the Mother-in-Law in several situations such as criticizing the Mother-in-Law's cooking (overcooked meal at dinner), consoling the Girl when she realizes she is not pregnant after all, and also after her mother reveals a lack of empathy in problematizing their mother-daughter relationship (in Part 2 of the scene) and the girl ends up in tears. A climax of the scene occurs at the end of Part 1, when the daughter leaves the frame to go to the bathroom and warns the two others beforehand not to get into a fight while she is away. Her mother and her boyfriend immediately start their heated confrontation after the Girl exits the frame. This exchange will be the object of closer investigation further below. 


\section{Narrative Structure, Content and Sequencing: Family Conflict Management strategies}

The mother represents what Klein and Johnson ${ }^{39}$ define as a "third party" in couple conflicts, i.e., friends or family members to whom authority is delegated in decisions of whom to ask for advice. According to Klein and Johnson the "third party" offers informal guidance and helps interpret the couple's conflicts, while also endorsing strategic choices to promote measures and attitudes conducive to more accommodative strategies for resolving conflicts.

In this connection I ask what power the couple has delegated to the mother as a "third party" participant, for whom does the mother advocate, and how is the mother's advocacy multimodally staged in particular versions? I would argue that primarily the daughter has delegated authority to her mother as her advocate in the relationship with the Guy, particularly if and when the daughter would like to create a family with a child but has encountered resistance from her partner, who has little enthusiasm for that prospect in the immediate future.

Even though the couple is unmarried, their relationship closely resembles that of a married household in that they cohabitate and have been committed to each other for many years ${ }^{40}$. In terms of Klein and Johnson's "dual concern" model of conflict management ${ }^{41}$, the couple integrates "mutual interests of self and other to each other's benefit" when conflict arises. The dual concern model presents four types of conflict management behaviours based on self and other considerations: 1) contending - which strives for high self-concern and low other-concern; 2) problem-solving - high self-concern and high other-concern; 3) yielding - low self-concern and high other-concern; 4) inaction - low self-concern, low other-concern. In various situations, each person may pursue one or more of these four conflict management strategies as a part of "constructive conflict management" and avoid "destructive negativity" or "negative reciprocity"42.

The dual-concern-model provides a basis for classifying the various family conflict management strategies performed in each of the shots containing conversations and activities of the three characters, both in the original Quebec version as well as most of the other versions under scrutiny in this study. The divergent or modified conflict management strategies of the characters in each shot of the different versions can be quantitatively measured for length/duration and even cross-culturally compared with each other as has been shown in the bar graphs above. Upon examining the shot in this scene, both the male and female protagonists (the Guy and the Girl) seem to be both pursuing "contending" attitudes towards the issue of pregnancy and child-raising. The male protagonist exhibits high selfconcern and low concern for her when he demonstrates his unpleasant surprise at the suggestion of his partner that she might be pregnant because her period is several hours late. His high self-concern and low concern for her also is manifested in his obvious relief that his partner is ultimately not pregnant, whereupon he performs varying degrees of regret and empathy with his partner in each version as a response to her sadness. The Girl exhibits a "contending" attitude towards her partner in that she openly expresses her wish for a pregnancy and takes no notice of her partner's shock at the suggestion that she might be pregnant, signalling that she hasn't consulted nor discussed it with him prior to her announcement. Below is an overview of the family conflict management strategies according to the dual concern model applied to the Part 1 and Part 2 shots of the Mother-in-Law scene. The Guy's visit to the Motherin-Law (in its entirety) represents a "yielding" strategy. Even though he was originally against the visit, the seduction by his girlfriend was successful and he yielded to her wish to visit her mother. The visit offered him an opportunity to defend himself, but it also revealed to the viewer the dubious nature and ostensible cause of the animosity between

39 Renate C.A. Klein and Michael P. Johnson, 'Strategies of Couple Conflict,' in Robert M. Mllardo, Steve Duck, eds, Families as Relationships, Wiley, 2000, p. 90.

40 Cf. Allen and Walker 2000, p. 13.

41 Klein and Johnson, 2000, p. $82 \mathrm{ff}$.

42 lbid., p. 87. 
E. Larkey, Narratological Approaches to Multimodal Cross-Cultural Comparisons of Global TV Formats

the two. The Girl's visit to her Mother, on the other hand, is pursuant to problem-solving strategies towards the Guy, because she is able to successfully entice him to come with her to her Mother in spite of the animosity between the two. The oral sex hinted at in the pre-visit shot solved the problem both for her as well as for the Guy.

\section{Toward a Transcultural Multimodal Analysis}

I will now undertake a multimodal analysis of that particular shot in the narrative of the Mother-in-Law visit in which there is a direct confrontation between the Guy and the Mother-in-Law without the mediation of the daughter. This represents the climax of the scene, since it is the longest in that part of the scene and resolves the open question of why there is an antagonism between the Guy and the Mother-in-Law, even though it doesn't resolve the conflict per se. This shot is at the end of the first part of the scene ${ }^{43}$, and is, in most versions, the longest shot in Part 1 , and is one of the more multimodally complex shots in that a "sad music" segment is deployed diegetically, but with a differing referent in various versions. While the duration of the music cue is between 19-32 seconds depending on the version, and therefore roughly the same length, its particular placement in the shot narrative leaves room for creating empathy with different characters present in the frame. These subtle differences will be explained further below. The interaction between the characters, the dialog, and the music forms a part of the multimodal configuration of the shot which can be subtly shifted or manipulated according to cultural or aesthetic proximity exigencies.

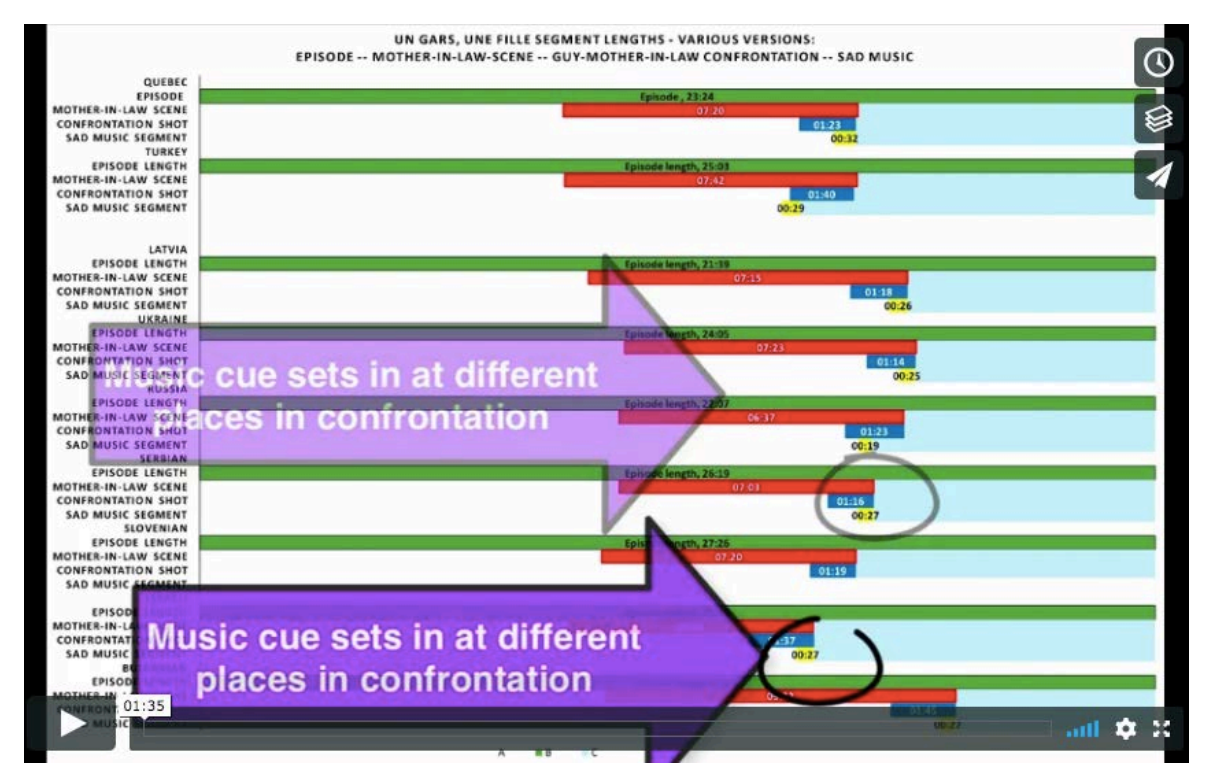

Video 5. Processing of table data on segment lengths of 10 versions of Un Gars, Une Fille showing length of Mother-in-Law episode (Part 1), the length of non-Mother-in-Law scenes in the episode, the length and location of the Mother-in-Law scene in the episode, the position and length of the confrontation shot between the Guy and the Mother-in-Law, the duration of scenes in the episode after the Mother-in-Law scene, the duration of pre-confrontation shots in the scene, and the length of the pre-music shots as well as the music cue durations in those shots, and the length of post music segments in those versions. The video also show how this table was transformed into the bar graph in Figure 4.

According to Jewitt ${ }^{44}$ multimodality "describes approaches that understand communication and representation to be more than about language, and which attend to the full range of communicational forms people use - image gesture, 
gaze, posture, and so on - and the relationships between them"45. Thus different modes of communication are precisely the elements which are included in determining cultural and aesthetic proximity. Jewitt states that all modes are semiotic resources which have the potential to contribute equally to meaning, and that these modes have been shaped through their cultural, historical and social uses to realize social functions. Meaning is configured by the selection and configuration of modes, whose interaction are crucial for meaning-making. Underlying my multimodal analysis of the various versions of Un Gars, Une Fille, therefore, is the understanding that each version represents a culturally specific multimodal audiovisual text with specific interactions and relationships between modes. The multimodal analyses of the different shots and the position of the music cue will therefore study the "interplay between modes to look at the specific work of each mode" and investigate how "each mode interacts with and contributes to the others in the multimodal ensemble" 46 .

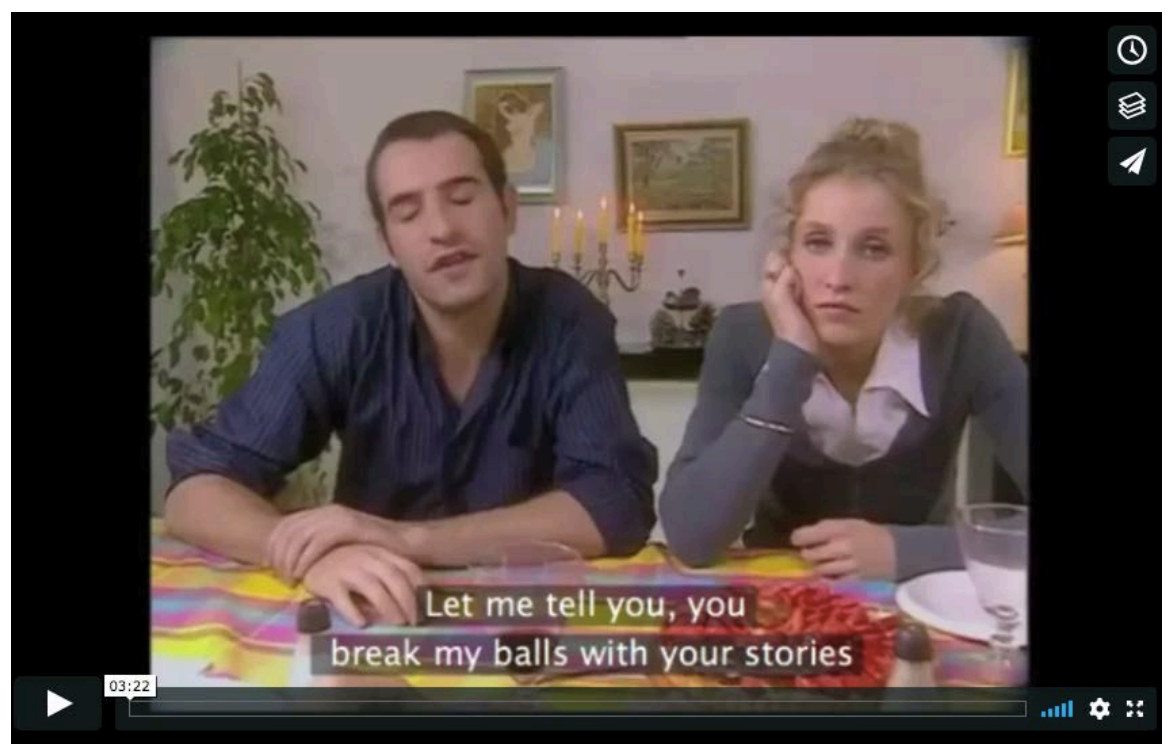

Video 6. Reaction of the different male protagonists to the Mother-in-Laws' accusations that they are "polygamists" and therefore are untrustworthy.

In the absence of the Girl, the Mother-in-Law asks the Guy if he doesn't like her, and the Guy confirms that he does not, and he professes to find no reason to like her. The Mother-in-Law replies that she doesn't like him either. The Guy then goads the Mother-in-Law into revealing to him, while the daughter is not present, why she doesn't like him. Calling him dishonest and insincere, she ultimately accuses him of being a polygamist (!). This absurd and outdated notion of infidelity elicits a response of varying degrees of incredulity from the Guy in the various versions, some of which are displayed in the short video segment of several versions Clip No. 6.

When the Girl returns to the table and thus interrupts the exchange between the two, she announces disappointedly that she is not pregnant after all. The Turkish version ${ }^{47}$ deviates from this in one important respect: she announces her non-pregnancy before she gets up from the table to go to the bathroom, which shifts the objective of the confrontation as well as its content to a different set of topics. The shot resolves one of the open developments since near the beginning of the first part, at the outset of which the Girl joyfully announces that her period is late and she is therefore probably pregnant, something she knows her mother would be quite happy about, but not her boyfriend, who is unpleasantly surprised by the news. This shot illustrates the extreme ambivalence of the female protagonist who, on 
the one hand, desires and enjoys more autonomy from the constraints of conventional heterosexual family structures, but also would like to accommodate the fulfilment of motherhood and family by having a baby. The finished table below indicates the lengths of each of the segments of this shot: the music within the conversation, the shot within the scene (Part 1), and the scene (Part 1) within the episode.

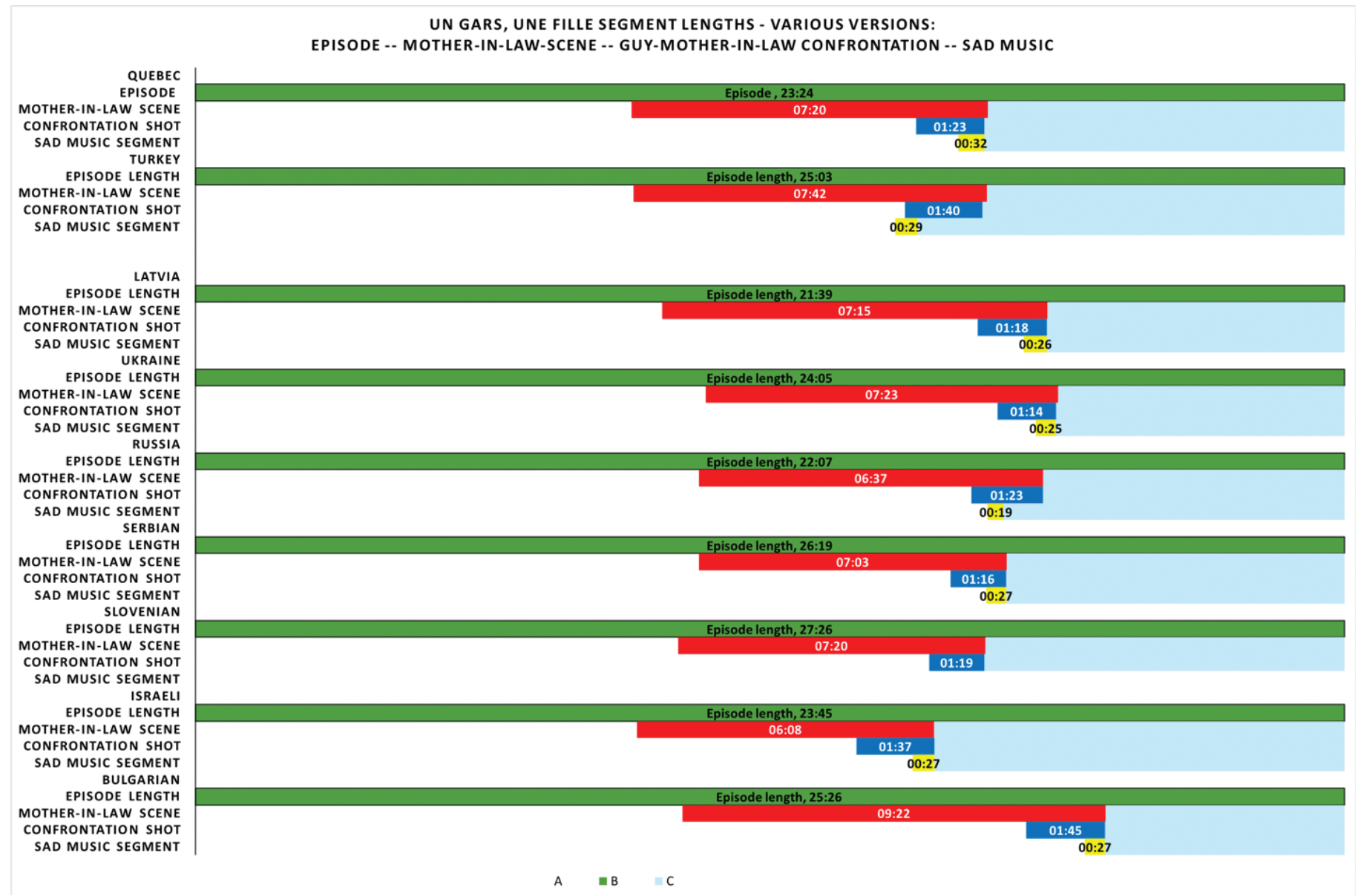

Figure 4. A bar graph showing the relative lengths of the episode, position and duration of the mother-in-law scene, elapsed time of the confrontation scene between the Guy and Mother-in-Law and the position and length of the sad music segment relative to all three of the previous segments. Please note the coordinated colour coding of the graph bars and the caption details.

The interrelationship between dialog, music, and movement in this particular shot comprises what ${ }^{48}$ terms a "modal configuration," which is the "hierarchical, equal, or connected relationships among modes that are at play at a given moment of higher-level action" 49 , whose interactions "are structured in relation to one another." The subtle temporal difference in the insertion of the "sad music" cue during this shot forms what Newfield ${ }^{50}$ calls a "transmodal moment," in which an idea is realized "in a new a different mode from that in which an idea was originally encountered" such that different modes "encourage or enable different interests to be realized" or create different perspectives on a topic.

48 Sigrid Norris, 'Modal density and modal configurations: multimodal actions,' in Carey Jewitt, ed, Routledge Handbook of Multimodal Analysis, Routledge, 2014.

49 Norris, 2004, p. 86

50 Denise Newfield, 'Transformation, transduction and the transmodal moment,' in Carey Jewitt, ed. Routledge Handbook of Multimodal Analysis, Routledge, 2014, p. 104. 
The utilization of sad music cues in this shot generates sympathy for different characters and ideas according to what character the music is making reference to in the shot, be it the Mother (Turkish version ${ }^{51}$ ), the Guy (Polish ${ }^{52}$ and Russian ${ }^{53}$ versions) or the Girl (Quebec, Ukrainiann ${ }^{54}$, Latvian ${ }^{55}$ ).

\section{Music Duration, Positioning, and Content during the Confrontation}

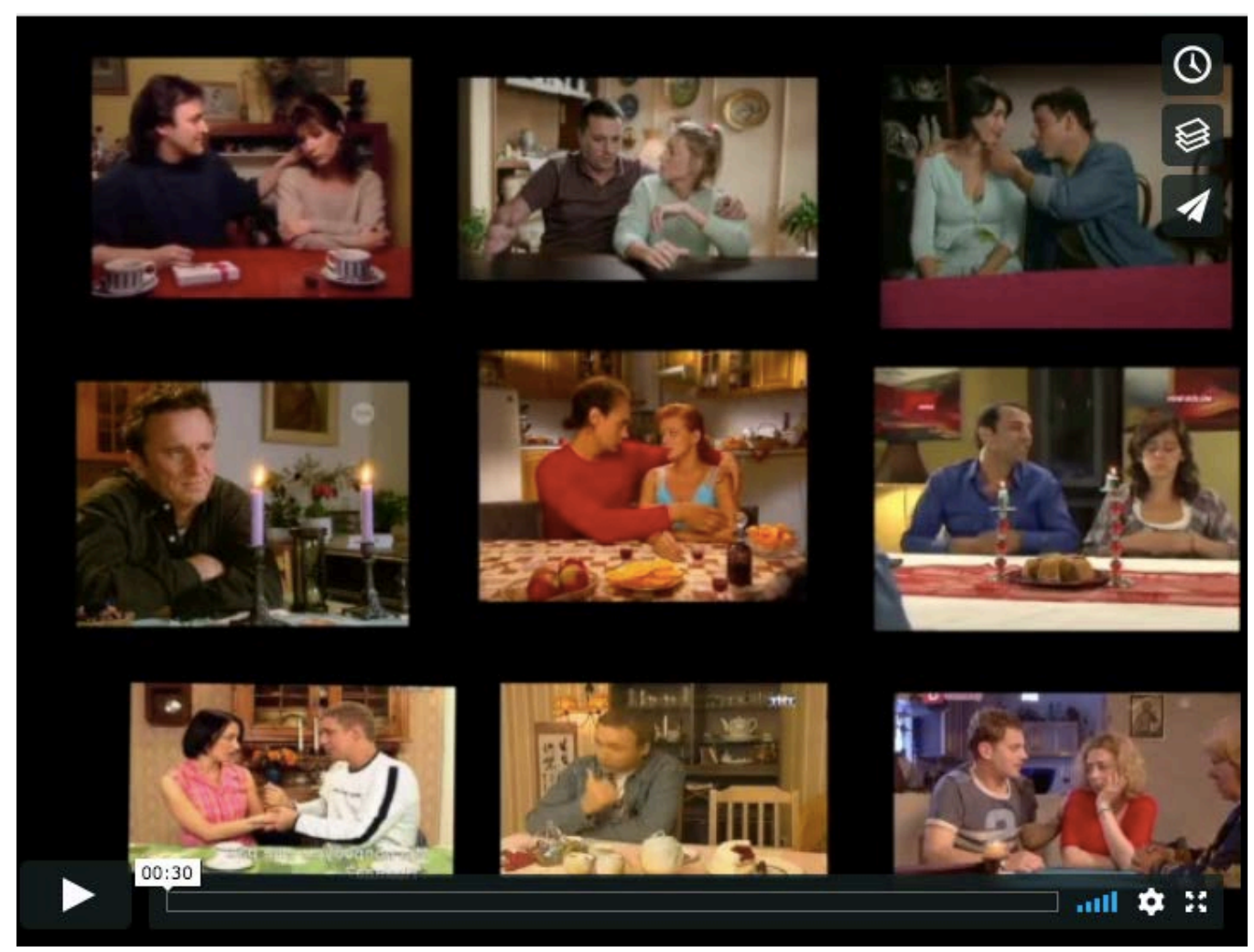

Video 7. This clip illustrates the different points at which the "sad music" cue sets in for the different versions of Un Gars, Une Fille (Part 1). Visible is the point at which the identical music segment sets in at different positions in each version. In most versions, the music starts when the Girl re-enters the room from the bathroom, while the Polish and Russian versions cue the music during the confrontation between the Guy and the Mother-in-Law. The Turkish version starts the music just after the Girl leaves for the bathroom.

The most frequent function of this music cue is to generate audience empathy with the Girl, who returns to the dining room table disappointed and sad that she is not pregnant. This is the case with the Quebec original version, as well as

51 Bir Kadın, Bir Erkek, 2008, Ep. 3: https://tune.pk/video/3622221/1-kadın-1-erkek-1sezon-3bölüm-türkmax accessed on Jan. 26, 2019.

52 'Kasia i Tomek,' Część 1, DBS-020, tvn/ITI DVD 2002.

53 Шаша и Maша, 2003-2005, THT, Ep. 2: https://www.youtube.com/watch?v=rp9hVTe6694\&list=PLSFxyBocXuT8YDpBr3ptFtXJuyaXpt07, accessed on January 25, 2019.

54 Леся и Рома (2005-2008, ICTV), Ep. 5, No longer available on Youtube.

55 Saldais Paritis, Ep 2: https://www.youtube.com/watch?v=xmPVvoKZEFE accessed on January 26, 2019. 
the Latvian ${ }^{56}$, the Serbian ${ }^{57}$, the Israeli ${ }^{58}$, the Bulgarian ${ }^{59}$, the Ukrainian ${ }^{60}$, and the Greek ${ }^{61}$ version. The music in these versions commences upon the Girl's re-entrance into the frame after going to the bathroom, and counteracts the Guy's apparent relief that she is not pregnant. Even though the Guy reveals his lack of enthusiasm for a potential pregnancy, he is still able to console the Girl and generate his own empathy with her, regardless of its lack of genuineness. Therefore, he is simultaneously fulfilling his responsibility towards his partner as well as creating empathy for his actions among the audience to sympathize with the woman. This coincides with the Mother-in-Law's ludicrous accusation that he is a "polygamist." His behaviour demonstrates his vacillating ambivalence between a "yielding" and a "contending" strategy of family conflict management, but the scene also reveals a lack of communication among the two protagonists about their future.

In some versions, the sad music commences just after the Girl leaves the frame, and continues during the confrontational conversation between the Guy and his Mother-in-Law. The dialog is usually initiated by the Guy, who goads the Mother-in-Law into revealing her reasons for her animosity towards the Guy. The conversation is conducted primarily by the Mother-in-Law during the music segment, with the camera focused on the Guy in a close-up shot. The music cue emphasizes the preposterousness of the Mother-in-Law's assertion that the Guy is a "polygamist" while creating sympathy with him in the face of the baselessness of the Mother-in-Law's beliefs. This is also the case with the Russian version, in which, similar to the Polish version, the music cue has already ceased upon the Girl's reentrance to the frame.

Finally, in the Turkish version, the Girl announced already in a shot prior to her exit from the frame that she is not pregnant, and the music commences while she is leaving to go to the bathroom. The sad music cue plays while the Mother-in-Law is interrogating the Guy, whose defensiveness stands in stark contrast to the male protagonists in the other versions. Intimating that the Guy is a loser because 1) he is not married; 2) the couple has no children; 3) his job is leading nowhere, the music signifies that he is a sad case for being such a loser in the eyes of the traditionally oriented Mother-in-Law, and that the Mother-in-Law deserves the sympathy and empathy in the face of his lack of personal and professional success. The dialog in the Turkish version is also quite different than those of the other versions in that the Mother-in-Law does not accuse the Guy of being a "polygamist." Instead, it is clear that she holds him in low regard for the above reasons. The sad music soundtrack terminates long before the return of the Girl.

A video clip containing 9 different versions of the visual, the dialog, and the music cue can be found in Fig. 4. The video clip plays the identical "sad music" cue at the varying visual points in each version, rendering visible the diverse character referents of the sad music in each different version.

\section{Concluding Remarks}

This article revolves around notions of globalization, hybridity and localization not from the standpoint of political economy, which looks critically at the power differentials inherent in the institutionalized production of audiovisual texts in globally operating capitalist media conglomerates and the markets in which they participate. It also doesn't focus on the flows or counter flows of audiovisual products in global distribution networks as commodities of trade and commerce. Instead, this article conceives of the multiple adaptations of the Quebec series Un Gars, Une Fille as

56 Ibid.

57 Andrija i Andelka, Ep 3: http://www.videoclip.bg/watch/4688

58 איהו אוה (He and She), 2002, Ep. 4: https://www.youtube.com/watch?v=wkpXEpKEAEQ

59 Тя й Той (2002-2004), Ep 3: https://noviseriali.com/тя-и-той-сезон-1-епизод-3_be60d6143.html

60 See Episode 5.

61 S’agapo, Magapas, 2010, Episode 3, MEGA. https://www.dailymotion.com/video/x3c4rhi, accessed on Feb. 2, 2019. 
audiovisual texts whose hybrid structure, content and sequencing contain global and local components structured and sequenced with traces of these power relationships and commercial mobilities.

In determining my narratological and multimodal approach, I follow Conway's ${ }^{62}$ notion of cultural translation extending beyond its usual linguistic realm to encompass "the materiality of television texts" for comparative textual analysis. Conway critiques adaptation studies for its avoidance of power relations governing the constitution of such texts. He also faults adaptation studies for evading the issue of how production and consumption logics create the adaptations, and finds fault with their neglect of the relevant decision-making processes leading to those products ${ }^{63}$. Conway emphasizes that cultural translation constitutes a "mode of participation in a semiotic economy where signs are exchanged for other signs" on the basis of negotiations which deposit residual evidence in the configuration of the textual structure and content. Conway underscores the task of the translator as an "act of mediation" in the more comprehensive negotiation of identities and social and political power in which "material traces" of translation and mediation can be found.

My study therefore accommodates Conway's effort to direct the researcher to the audiovisual text as a material object of investigation with a history, structure and content. My contribution goes a step further in suggesting that computer annotation software be utilized to make quantitatively precise determinations about the lengths and durations of multimodal configurations constituting the narrative structure, content and sequencing of each version. These may be compared with each other transculturally within the context of universal discourses such as those relating to gender roles, identities and family relations within a nation, as I have illustrated further above.

Uribe-Jongbloed and Espinosa-Medina ${ }^{64}$ engage in a critical review of the notion of cultural proximity and distanciation as determinants for the way format adaptations are created. In distinguishing between the view of cultural proximity as a property of the market compared to another market, they direct their attention to the product "which is inserted into a given market" and "includes components that make it easy to understand by audiences in different cultural contexts"65, originally suggested by Straubhaar and La Pastina ${ }^{66}$ in advocating for complementing cultural proximity with what they call "shareability", a product-oriented viewpoint. Straubhaar and La Pastina hypothesize that "a given product created in a particular market may have a high level of shareability in those markets which have high cultural proximity to the cultural market where it was created." I would, however, expand the notion of shareability beyond a seemingly random or arbitrary assemblage of properties or characteristics included in the respective versions to accommodate vaguely defined market exigencies. Instead, these aspects participate in an ideologically coherent, and shared and contested, negotiated public and global discourse in which all versions are engaged through the respective narratives.

Uribe-Jongbloed and Espinosa-Medina describe a process by which cultural transductors act as intermediaries involved in the transfer of cultural products to consumers and work between cultures ${ }^{67}$. They decide what components of the narrative should be retained and which should be modified. They drive the hybridization process by determining the form and selecting and modifying the texts. The transductors subject the texts to processes of de- a-, and reculturalisation, whereby de-culturalisation reduces the elements that affect the shareability of the product by eliminating as many culturally dependent elements as possible, while re-culturalisation modifies the original text by removing elements which the audience might not have the tools or background to understand (such as language or humour), while comprehending the overall values ${ }^{68}(35)$. My study provides much more precise knowledge on what

62 Kyle Conway, 'Cultural Translation, global television studies, and the circulation of telenovelas in the United States,' International Journal of Cultural Studies, 15,6, 2012, pp. 583-598.

63 Conway, 2012, p. 584.

64 Enrique Uribe-Jongbloed, Hernán David Espinosa-Medina, 'A clearer picture: Towards a new framework for the study of cultural transduction in audiovisual market trades,' Observatorio Journal, 8, 1, 2014.

65 Ibid., p. 32.

66 La Pastina and Straubhaar, 'Multiple Proximities between Television Genres and Audiences,' Gazette. The International Journal for Communication Studies, 67, 3, 2005, pp. 271-288.

67 Uribe-Jongbloed and Espinosa-Medina, 2014, p. 37.

68 Ibid., p. 35 
has been re-culturalized in the various textual versions of Un Gars, Une Fille, and how re-culturalization is accomplished by re-configuring the different modes of communication in each different version, and how each different version can be constituted as a multimodal audiovisual text comprising part of particular contested discourses on social, political, gender, family, and cultural identities. Each component of a narrative such as that in Un Gars, Une Fille is therefore not only just a separate object that may be modified, deleted, or added in the course of adaptation, but they instead form a part of an underlying discourse whose realization in the adaptation is the product of negotiation among a series of transductors involved in its production, distribution and consumption.

Uribe-Jongbloed and Espinosa-Medina propose the concept of "discourse proximity", which is when a "product has an affinity with a company-implanted discourse"69. I would propose a deeper and also more extensive examination of the concept of discourse proximity to evaluate its advantages and disadvantages compared to notions of cultural proximity (Straubhaar) or aesthetic proximity (van Keulen).

In her notion of aesthetic proximity, van Keulen attributes the "local" of the format adaptations to "style elements", comprised of "cinematography, editing and sound" and thus "surface," which makes the global format culturally proximate $^{70}$. On the other hand, she postulates "a growing transnational aesthetic" inherent in the format ${ }^{71}$, prompted by transnational exchange of production practices, the format bible, and and ideas. My multimodal and narratological investigation indicates that even though aesthetic styles may be transnationally standardized and seemingly universal, sometimes barely perceptible changes in modal configurations may be deployed to produce ideologically diverging televisual narratives in each iteration of the format. I propose that aesthetic and stylistic techniques are the building blocks for creating discursively viable, globally, regionally, and locally contested identity narratives. At the level of political economy, a production-focused approach may capture the power relationships underlying the international format trade, and a distribution approach may describe the market conditions under which the transducers and cultural translators attempt to create a culturally proximate product. However, the narrative result - its content, structure, and sequencing - is the determining factor for the audience reception and acceptance.

Combining a multimodal with a narratological analysis lends itself to delineating the "process of transforming a cultural product for its integration into another market" and comprehend "the elements that make a product shareable or not"72. Discourse proximity lends itself to multimodally configured identity discourses circulating and contested in society at many different levels and conducted by different groups. My study outlines a precise procedure for including narratological and multimodal knowledge into determining the different kinds of strategies involved in creating "discourse proximity". This was accomplished in the multimodal analysis of the Mother-in-Law scene of the different versions in which a slight shift in the timing of the music cue signalled a major departure from discourses of gender and family in other versions. Determining the lengths of the narrative segments - shots and scenes - is also a means of asking further questions of transductors about shifts in narrative structure and sequencing as well as de- and re-culturation strategies that could be a part of further ethnographic analyses and audience reception studies.

\section{Bi o graph y}

Edward Larkey is Professor of German Studies and Intercultural Communication in the Department of Modern Languages, Linguistics, and Intercultural Communication at the University of Maryland, Baltimore County (USA). He obtained his Dr. Phil at the Humboldt- Universität in Berlin in 1986 in Cultural Studies. After publishing two 
E. Larkey, Narratological Approaches to Multimodal Cross-Cultural Comparisons of Global TV Formats

books on the transcultural diffusion of US pop music in Austria (1993) and the German Democratic Republic (2007), he turned his interest to the study of global television format adaptations. His current focus is on multimodal theories and methodologies of cross-cultural comparison using computer- generated data to expand a hermeneutic approach to narrative analysis. He has since published several articles and book chapters expounding on this approach. He is currently working with a group of international scholars comparing the Quebec TV series Un Gars, Une Fille. 